\title{
Introduction to the symposium on bubbles, multiple equilibria, and economic activities
}

\author{
Jianjun Miao ${ }^{1,2,3}$
}

Received: 19 January 2016 / Accepted: 20 January 2016 / Published online: 2 February 2016

(C) Springer-Verlag Berlin Heidelberg 2016

The recent financial crisis has damaged the reputation of macroeconomics and prompted researchers to rethink the core of modern macroeconomics. The current core is the dynamic stochastic general equilibrium (DSGE) approach. This approach is based on the assumptions of rational expectations, intertemporal optimization, and market clearing and hence is coherent. Moreover, DSGE models can be calibrated and estimated to provide quantitative predictions and may be useful for policy analysis. However, these models fail to explain many puzzling phenomena in finance and macroeconomics. Besides the celebrated equity premium puzzle, there are many questions we still do not know much. For example, what are the sources of business cycles? Why are stock markets so volatile? Does the stock market comove with the real economy and how can one explain their relationship? What is the role of banks and credit markets and how do they impact the real economy?

Standard DSGE models typically feature a unique deterministic steady state. The steady state is determinate and intrinsically stable in the sense that in the absence of exogenous aggregate shocks, the economy would tend toward the steady state. Economic fluctuations are then driven by various sorts of exogenous shocks. These shocks could come from the demand side or the supply side and include technology shocks, preference shocks, financial shocks, news shocks, and uncertainty shocks. These shocks must face two questions: Can a small shock generate a large and per-

I would like to thank Jess Benhabib for helpful comments.

Jianjun Miao

miaoj@bu.edu

1 Department of Economics, Boston University, 270 Bay State Road, Boston, MA 02215, USA

2 CEMA, Central University of Finance and Economics, Beijing, China

3 AFR, Zhejiang University, Hangzhou, China 
sistent economic fluctuation? Can a shock generate comovement of consumption, investment, unemployment, output, and asset prices? Unfortunately, almost all shocks in the DSGE literature cannot satisfactorily resolve these two questions simultaneously despite the fact that this literature has provided many important amplification and propagation mechanisms, e.g., the financial accelerator mechanism (Kiyotaki and Moore 1987; Bernanke et al. 1999).

Recently, there has been a revival of interest in models with multiple equilibria and models with complex dynamics. ${ }^{1}$ These models may have a unique steady state, which is indeterminate. Thus, sunspot equilibria can arise, and economic fluctuations can be driven by sunspot shocks, which are unrelated to economic fundamentals. In some cases, multiple steady states can exist. Some of them are stable and others are not. Sunspot shocks can trigger the economy to shift from one steady state to another. Even in the absence of any shocks, a deterministic equilibrium system can exhibit chaotic dynamics or periodic orbits, which resemble stochastic paths.

The purpose of this symposium is to promote research on models with the preceding features because they are useful to explain many issues such as asset bubbles, collateral shortages, liquidity dry-up, bank runs, and financial crises that played a central role in the recent global recession. These issues, however, often belong to the periphery of macroeconomics (Caballero 2010). All seven papers in this symposium study part of these issues and related policy implications.

One early critique of models with sunspot equilibria or with complex dynamics is that they typically lack solid microfoundations and are quantitatively implausible. As Benhabib and Farmer (1999) point out, these models must violate some assumptions underlying the Arrow-Debreu general equilibrium theory. Typical violations include (1) incomplete market participation as in the overlapping-generations (OLG) model; (2) incomplete markets due to transactions costs or information asymmetry; (3) increasing returns to scale (IRS) in the technology; (4) market imperfections associated with fixed costs, entry costs, or external effects; and (5) the use money as a medium of exchange. One can add many others to this list such as imperfect contract enforcement, search and matching, credit constraints, and agency conflict.

Dong et al. (2015) provide a search-based model to formalize the Austrian idea of business cycles, which emphasizes bank issuance of credit as the main cause of economic fluctuations. Their model features three types of agents: a representative household with a continuum of ex ante identical members (depositors), a representative bank with a continuum of ex ante identical loan officers, and a continuum of firms. The bank accepts deposits from the household through search and matching and then lends to firms also through search and matching. Excess reserves and credit rationing can coexist because some bank deposits are not matched with firms and some firms are not matched with loans. They show that the aggregate production function exhibits local IRS even though the underlying micro-level production and matching technologies both exhibit constant returns to scale. This endogenous source of local IRS arising from procyclical credit utilization can in turn generate local indeterminacy and self-fulfilling credit cycles that feature a powerful multiplier-accelerator propagation mechanism.

\footnotetext{
1 Recent surveys of this literature include Guesnerie and Woodford (1992), Benhabib and Farmer (1999).
} 
The model of Dong et al. provides a microfoundation of the Benhabib and Farmer (1994) model with IRS and the Wen (1998) model with a variable rate of capital utilization under IRS. One early critique of the Benhabib-Farmer-Wen model is that the parameter values for the aggregate IRS to generate indeterminacy may be quantitatively implausible. The beauty of the microfounded Dong-Wang-Wen model is that this model can generate indeterminacy with much more plausible parameter values at the micro-level. Moreover, the introduction of the banking sector and the modeling of credit frictions are relevant for understanding episodes of financial crises.

Since the seminal contributions of Samuelson (1958), Diamond (1965), and Tirole (1985), it has been well known that the OLG model can generate asset bubbles and multiple equilibria. This type of model features two steady states: One is bubbly, and the other is bubbleless. The key condition for the existence of a bubble is that the economy must be dynamically inefficient or the interest rate must be sufficiently low in the bubbleless equilibrium. Thus, capital is overaccumulated in the bubbleless equilibrium, and a bubble can crowd out capital and achieve dynamic efficiency. Three problems arise in this framework. First, dynamic inefficiency is not supported in the data as documented by Abel et al. (1989). Second, bubbles are welfare improving and the collapse of bubbles generates a boom in capital, a prediction inconsistent with the data. Third, the existing overlapping-generations models typically study a two- or three-period setup. The model period cannot relate to the calendar time, and hence, these models are impossible to quantify. Since the existence of asset bubbles is a quantitative observation, it is important to develop infinite-horizon models of bubbles for a quantitative study. ${ }^{2}$

Ikeda and Phan (2015) provide an OLG model with toxic bubbles by incorporating a banking sector. Households make deposits in banks, and banks make risky investment. The risky investment is a bubble asset that can collapse with some probability. Since bankers are protected by limited liability, they have incentives to shift risk to depositors. In contrast to the standard Samuleson-Diamond-Tirole model, this risk-shifting leads to welfare-reducing rational asset bubbles. Ikeda and Phan then study several types of policy to deal with toxic bubbles. First, they study the policy that the government can prick the bubble, assuming that the bubble is observable. They show that if the bubble is sufficiently risky, then pricking the bubble in period $T$ can improve the welfare of all generations born in periods $t \geq T$. At the same time, pricking the bubble hurts the current bubble holders (the old households in period $T$ ). They also show that if there is a one-time redistribution in the same period from the young to the old; then, every generation is better off.

Ikeda and Phan also study two ex ante anticipated policies: macroprudential policy that taxes bubble speculation and a macroprudential banking regulation that places a constraint on the share of a risky asset in bankers' balance sheets. For each policy, they show that the riskier a bubble, the higher is the optimal tax or the tighter is the optimal constraints on bankers. In addition, both policies can eliminate toxic asset bubbles. Finally, Ikeda and Phan study a policy that restricts leverage. They show that toxic bubbles can be eliminated if the leverage restriction is sufficiently tight.

\footnotetext{
${ }^{2}$ See Miao (2014) for a recent survey of this literature.
} 
Miao et al. (2015) provide an infinite-horizon model to study the relationship between stock market bubbles and unemployment. Evidence shows that stock market bubbles are often associated with economic booms and the stock market crashes are often associated with economic recessions. For example, during the recent Great Recession, the unemployment rate rose from 5.0 at the onset of the recession to a peak of 10.12009, while the stock market fell by more than 50 October 2007 to March 2009. Unfortunately, standard macroeconomic models often treat the stock market as a sideshow and ignore its role when studying macroeconomic quantities such as investment, consumption, unemployment, and output.

By contrast, Miao et al. take up this issue by introducing credit constraints into a search and matching model. In particular, firms must borrow to finance investment and hiring costs. But debt contract is imperfectly enforced. If a firm default, it is reorganized and the lender gets the stock market value of the reorganized firm (goingconcern value). Thus, in an optimal contract with limited commitment, debt is limited by this value. This type of credit constraints is different from that in Kiyotaki and Moore (1987) and is first introduced by Miao and Wang (2011) and has been applied to study many other macroeconomic issues (Miao and Wang 2012, 2014, 2015; Miao et al. 2015a,b). An important implication of this type of credit constraints is that it can generate a stock market bubble through a positive feedback loop mechanism. The intuition is the following: When investors have optimistic beliefs about the stock market value of a firm's assets, the firm wants to borrow more using its assets as collateral. Lenders are willing to lend more in the hope that they can recover more if the firm defaults. Then, the firm can finance more investment and hiring spending. This generates higher firm value and justifies investors' initial optimistic beliefs. Thus, a high stock market value of the firm can be sustained in equilibrium.

The stock market bubble is risky because it may burst with some probability in the future. When all agents hold this belief, it can be self-fulfilling and causes a stock market crash. After the crash, the credit constraints are tightened, causing firms to reduce investment and hiring. As a result, the economy enters a recession with a persistently high unemployment rate. Miao and Wang show that changes in confidence or beliefs can cause an equilibrium regime shift in that the economy can switch from one steady state to another.

Large fiscal deficits and rising stocks of public debt in many advanced economies, especially in the aftermath of the Great Recession, raise concerns about debt sustainability. When public debt is not backed by taxes, it is a bubble. Thus, the question of debt sustainability is essentially related to the study of bubbles. Kaas (2015) examines the effect of public debt and fiscal deficits on TFP using a tractable dynamic general equilibrium model with credit market imperfections and heterogeneous firms facing idiosyncratic productivity shocks. He shows that if the credit constraints are sufficiently tight, low interest rates permit the government to run Ponzi schemes, i.e., to roll over unbacked government debt indefinitely, so that permanent primary deficits can be sustained. Such economies typically have two steady states. One steady state has a larger stock of public debt, a higher interest rate, and a more efficient factor allocation, but at the same time less private credit and capital. This steady state is generally unstable and can only be sustained if the price of government bonds is a bubble. In the absence of such a bubble, the economy converges to the other, stable steady 
state at which TFP and the interest rate are lower, while private credit and capital are larger.

Kaas derives the maximum sustainable deficit ratio quantitatively by calibrating the model to match long-run features of the US economy. He finds that the maximum sustainable primary deficit is quite small, amounting to less than 1 much lower than that found in a quantitative overlapping-generations model.

Since the seminal contribution by Diamond and Dybvig (1983), the literature on bank runs has been growing. Models of bank runs provide a classical example of the importance of models with multiple equilibria. One early critique of the models with multiple equilibria is that they cannot yield definite predictions, and hence, they are not useful for policy analysis. One line of research as in game theory tries to refine equilibria and reduce the set of equilibria. As Woodford (1987) argues, models with a unique determinate equilibrium do not necessarily outperform models with multiple equilibria both conceptually and empirically. For example, models with a unique equilibrium typically need many unobserved shocks to explain the data as demonstrated in the recent Bayesian DSGE literature (see An and Schorfheide 2007 for a survey). This is not much different from models with multiple equilibria because one can view sunspots or shifts in beliefs as one of the unobserved shocks (Miao et al. 2015a). More importantly, studying the conditions for the existence of multiple equilibria is critical for policy analysis. For example, in the literature on bank runs, investigating what particular institutional arrangements, such as deposit insurance or suspension of convertibility in certain circumstances, can suppress such equilibria is critical for policy analysis.

Ennis and Keister (2015) study a finite-depositor version of the Diamond-Dybvig model of financial intermediation in which banks and all depositors observe withdrawals as they occur. The assumption about sequential service and the information structure is critical for the existence of bank runs. For example, under the assumption in Green and Lin (2003), bank runs cannot occur. By contrast, under the assumption in Ennis and Keister (2015), their model can explain many interesting phenomena, for example, the face-value property of demand deposits, sharp discounts during crises, and partial bank runs.

Ennis and Keister do not conduct a policy analysis. Cooper and Kempf (2015) take up this issue and study the effects of the orderly liquidation of a failing bank and the ex post provision of deposit insurance on the prospect of bank runs. In the framework of Diamond and Dybvig (1983), if agents believe that deposit insurance will be provided, then bank runs driven by beliefs will never occur. In equilibrium, the government need not act: Deposit insurance is never provided, and costly liquidations are avoided. Instead, deposit insurance works through its effects on beliefs, supported by the commitment of a government to its provision.

However, government commitment cannot be guaranteed in practice. Cooper and Kempf (2015) consider the other extreme case in which the government lacks commitment power and its interventions are chosen and undertaken ex post. The costs of liquidation and redistribution across heterogeneous households play key roles in the policy choice. If investment is sufficiently illiquid, a credible liquidation policy will deter bank runs. Deposit insurance funded by an ex post tax scheme will be provided unless it requires a socially undesirable redistribution of consumption that outweighs 
insurance gains. If taxes are set optimally ex post, bank runs are prevented by deposit insurance without costly liquidation; if not, a combination of the two policies will prevent bank runs.

Models with bank runs are typically confined to a two- or three-period setup. This setup is useful to understand economic intuition transparently, but it is too stylized and abstract away from some truly dynamic aspects of the costs and benefits tradeoff. Benhabib et al. (2015) introduce a banking sector into an infinite-horizon model. The bank can undertake a safe project and a risky project. The risky project is socially inefficient, but bankers may still invest in it because they are protected by limited liability and can shift risk to depositors. ${ }^{3}$ In an optimal contract between bankers and depositors, bankers are deterred from risk-shifting. This is achieved by incentive compatibility constraint which ensures that the bank franchise value deters bank owners from investing in excessively risky assets. By definition, the franchise value is equal to the present discounted value of payouts from operating the bank, and hence, it contains a component of the reputation value. This component depends on beliefs and can generate multiple equilibria in the model.

The intuition for the existence of multiple equilibria is as follows. When high future deposits imply a high franchise value in the future, investing in risky assets using current deposits and endangering the future value of the franchise value becomes more costly. The banker does not have an incentive to invest in the risky project, and hence, the incentive constraint is relaxed. This in turn raises the amount of deposits that the banker can borrow today. Thus, the optimistic belief about future high deposits can be self-fulfilling. Similarly, the pessimistic belief about low future deposits can also be self-fulfilling. This dynamic complementarity across time is different from the static complementarity in the Diamond and Dybvig (1983) model. In the Diamond-Dybvig model, a depositor will withdraw his deposit early if he thinks the others will do so as well, so a bank run will occur.

Benhabib et al. show that multiple steady states can exist. Moreover, the model features a continuum of non-stationary chaotic equilibria, as well as equilibria with "branching" dynamics, that is, equilibrium dynamics described by difference correspondences with multiple values at each point in time, instead of the standard dynamics of difference equations. Benhabib, Miao, and Wang show that the steady state with the highest deposits Pareto dominates other steady states, but the local equilibrium dynamics around this steady state are complex and cause instability of the economy. The policymaker then faces a tradeoff: To maintain stability by removing complex equilibria around the steady state with high deposits will reduce the household welfare. Benhabib et al. (2015) study several types of policies. First, imposing a ceiling on the deposit rate or Regulation Q in the US that capped the interest on deposits can eliminate the high-deposit steady state. Second, leverage ratio restrictions can achieve a unique equilibrium with a low deposit level. Third, the government can design a feedback rule of discount window lending policy such that the economy achieves the second-best steady-state equilibrium with high deposits.

3 This feature is similar to that in Ikeda and Phan (2015). 
In summary, the seven papers in this symposium have contributed to the literature in various dimensions. The traditional models of bubbles and multiple equilibria typically use the OLG framework. Some of the papers in this symposium use the infinite-horizon framework and obtain many new insights outside of the OLG framework. Moreover, Kaas shows that his infinite-horizon model gives quantitatively different predictions than OLG models. Macroeconomic models must be eventually confronted with the data. Otherwise, theory is vacuous. All papers in this symposium are theoretical, albeit some of them contain calibration exercises. In terms of future research, it would be fruitful to develop more theoretical studies that can be potentially quantified. Moreover, it would be exciting to conduct quantitative or empirical studies based on models with multiple equilibria. Finally, none of the papers in this symposium has touched questions related to money and monetary policy. Further research in this direction would also be needed.

\section{References}

An, S., Schorfheide, F.: Bayesian analysis of DSGE models. Econ. Rev. 26, 113-172 (2007)

Abel, A.B., Mankiw, N.G., Summers, L.H., Zeckhauser, R.J.: Assessing dynamic efficiency: theory and evidence. Rev. Econ. Stud. 56, 1-19 (1989)

Benhabib, J., Farmer, R.E.A.: Indeterminacy and increasing returns. J. Econ. Theory 63, 19-41 (1994)

Benhabib, J., Farmer, R.E.A.: Indeterminacy and sunspots in macroeconomics. In: Taylor, J., Woodford, M. (eds.) Handbook of Macroeconomics, vol. 1A, pp. 387-448. North-Holland, Amsterdam (1999)

Benhabib, J., Miao, J., Wang, P.: Chaotic banking crises and regulations. Econ. Theory (2015). doi:10.1007/ s00199-015-0928-1

Bernanke, B., Gertler, M., Gilchrist, S.: Financial accelerator in a quantitative business cycle framework. In: Taylor, J., Woodford, M. (eds.) Handbook of Macroeconomics. Elsevier Science, Amsterdam (1999)

Caballero, R.J.: Macroeconomics after the crisis: time to deal with the pretense-of-knowledge syndrome. J. Econ. Perspect. 24, 85-102 (2010)

Cooper, R., Kempf, H.: Deposit insurance and bank liquidation without commitment: can we sleep well? Econ. Theory (2015). doi:10.1007/s00199-015-0928-1

Diamond, D.W., Dybvig, P.H.: Bank runs, deposit insurance, and liquidity. J. Polit. Econ. 91, 401-419 (1983)

Diamond, P.: National debt in a neoclassical growth model. Am. Econ. Rev. 55, 1126-1150 (1965)

Dong, F., Wang, P., Wen, Y.: Credit search and credit cycles. Econ. Theory (2015). doi:10.1007/ s00199-015-0928-1

Ennis, H.M., Keister, T.: Optimal banking contracts and financial fragility. Econ. Theory (2015). doi:10. 1007/s00199-015-0928-1

Green, E.J., Lin, P.: Diamond and Dybvig's classic theory of financial intermediation. J. Econ. Theory 109, 1-23 (2003)

Guesnerie, R., Woodford, M.: Endogenous fluctuations. In: Laffont, J.-J. (ed.) Advances in Economic Theory: Proceedings of the Sixth World Congress, vol. II. Cambridge University Press, Cambridge (1992)

Ikeda, D., Phan, T.: Toxic asset bubbles. Econ. Theory (2015). doi:10.1007/s00199-015-0928-1

Kaas, L.: Public debt and total factor productivity. Econ. Theory (2015). doi:10.1007/s00199-015-0928-1

Kiyotaki, N., Moore, J.: Credit cycles. J. Polit. Econ. 105, 211-248 (1987)

Miao, J.: Introduction to economic theory of bubbles. J. Math. Econ. 53, 130-136 (2014)

Miao, J., Wang, P.: Bubbles and credit constraints. In: Working Paper, Boston University (2011)

Miao, J., Wang, P.: Bubbles and total factor productivity. Am. Econ. Rev. 102, 82-87 (2012)

Miao, J., Wang, P.: Sectoral bubbles, misallocation, and endogenous growth. J. Math. Econ. 53, 153-163 (2014)

Miao, J., Wang, P.: Banking bubbles and financial crises. J. Econ. Theory 157, 763-792 (2015)

Miao, J., Wang, P., Xu, L.: Stock market bubbles and unemployment. Econ. Theory (2015). doi:10.1007/ s00199-015-0928-1 
Miao, J., Wang, P., Xu, Z.: A Bayesian DSGE model of stock market bubbles and business cycles. Quant. Econ. 6, 599-635 (2015)

Miao, J., Wang, P., Zhou, J.: Asset bubbles, collateral, and policy analysis. J. Monet. Econ. 76, S57-S70 (2015)

Samuelson, P.A.: An exact consumption-loan model of interest with or without the social contrivance of money. J. Polit. Econ. 66, 467-482 (1958)

Tirole, J.: Asset bubbles and overlapping generations. Econometrica 53, 1499-1528 (1985)

Wen, Y.: Capacity utilization under increasing returns to scale. J. Econ. Theory 81, 7-36 (1998)

Woodford, M.: Three questions about sunspot equilibria as an explanation of economic fluctuations. Am. Econ. Rev. 77, 93-98 (1987) 